\title{
Utilização de radiação gama e amido de milho no armazenamento pós- colheita das folhas de couve manteiga
}

\author{
Alex Guimarães Sanches ${ }^{1}$, Jaqueline Macedo Costa ${ }^{1}$, Maryelle Barros da Silva ${ }^{1}$, Elaine Gleice \\ Silva Moreira ${ }^{1}$
}

${ }^{1}$ Universidade Federal do Pará, Campus de Altamira, Altamira, PA, Brasil. E-mail: alexsanches.eng@gmail.com, jakcosta@hotmail.com, maryelle@bol.com.br, elaine.moreira.230@gmail.com

Recebido: 16/07/2016; Aceito: 30/08/2016.

\section{RESUMO}

Devido à alta perecibilidade apresentada pelas folhas de couve-manteiga após a colheita, o presente trabalho teve por objetivo avaliar o efeito isolado e combinado da radiação gama e amido de milho visando o prolongamento de sua vida útil. $O$ delineamento experimental utilizado foi o inteiramente casualizado em esquema fatorial 4 x $9 \mathrm{com}$ cinco repetições e os parâmetros teor de clorofila, atividade das enzimas POD e PPO, sólidos solúveis, pH, acidez titulável, perda de massa fresca, murchamento, sabor e qualidade geral foram avaliados a cada dois dias. De acordo com os resultados observou-se interação significativa a nível de 5\% de probabilidade pelo teste $\mathrm{F}$ em todos os parâmetros avaliados. A utilização do amido de milho na forma isolada apresentou resultados semelhantes à testemunha, do mesmo modo, o efeito combinado de amido de milho e radiação gama não diferiu quando comparada ao efeito isolado da radiação gama. O efeito isolado da radiação gama em todas as características avaliadas apresentaram os melhores resultados principalmente no que diz respeito ao teor de sólidos solúveis, acidez titulável, teor de clorofila e sabor.

Palavras-chave: Brassica oleracea L. var. acephala, folhosa, hortaliça.

\section{Radiation use range and corn starch in leaves post-harvest storage collard greens}

\begin{abstract}
Due to the high perishability presented by the kale leaves after harvest, this study aimed to evaluate the single and combined effect of gamma radiation and maize starch aimed at prolonging its life. The experimental design was completely randomized in a factorial $4 \times 9$ with five repetitions and parameters: chlorophyll content, activity of enzymes POD and PPO, soluble solids, $\mathrm{pH}$, titratable acidity, loss of weight, wilting, flavor and overall quality were evaluated every two days. According to the results there was significant interaction at the level of $5 \%$ probability by the $\mathrm{F}$ test for all parameters. The use of maize starch alone showed similar results to the control, in the same manner, the combined effect of maize starch and the gamma radiation was not different compared to the isolated effect of gamma radiation. The isolated effect of gamma radiation on all traits showed the best results especially in relation to soluble solids, titratable acidity, chlorophyll content and flavor.
\end{abstract}

Key-words: Brassica oleracea L. var. acephala, leafy vegetables, vegetable. 


\section{Introdução}

A couve manteiga (Brassica oleracea L. var. acephala) é uma hortaliça arbustiva anual, da família Brassicaceae, cujo consumo no Brasil tem gradativamente aumentado devido, provavelmente, às novas maneiras de utilização na culinária e às recentes descobertas da ciência quanto às suas propriedades nutracêuticas (NOVO et al., 2010).

É uma hortaliça cuja folha é a parte comestível, sendo rica em vitamina $\mathrm{A}$ e $\mathrm{C}$ e muito apreciada na culinária, apresentando preferência quando encontra-se recém colhidas, verdes e sem sinais de desidratação e podridões (FILGUEIRA, 2003). No entanto, devido ao alto metabolismo, suas folhas possuem elevada perecibilidade, tendo como indicativos o amarelecimento e a perda de turgor causando consequente curto período pós-colheita.

Com isso, torna-se necessária a busca por processos que possam propiciar aumento da vida pós-colheita dessa espécie, que apresenta uma literatura muito escassa no que diz respeito à sua conservação póscolheita. A utilização da radiação gama e do amido de milho são agentes atenuantes da preservação e da qualidade pós-colheita.

A radiação gama associada aos procedimentos póscolheita é um excelente método para prolongar a vida comercial das frutas, retardando os processos de amadurecimento e senescência, bem como reduzindo significativamente o apodrecimento causado por fungos e bactérias patogênicas (VIEITES et al., 2012).

O uso de revestimentos comestíveis como o amido de milho tem recebido bastante atenção de pesquisadores nos últimos anos, graças principalmente às suas propriedades de barreira, reduzindo o metabolismo dos vegetais, de melhoria da aparência, da integridade estrutural e das propriedades mecânicas do alimento, prolongando assim, a vida pós-colheita (AZEREDO et al., 2000; ALVES et al., 2011).

Nesse contexto, o presente trabalho teve por objetivo avaliar a utilização da radiação gama e do amido de milho na conservação pós-colheita das folhas de couve manteiga, verificando, assim, sua eficácia na redução do processo de senescência

\section{Material e Métodos}

Folhas de couve manteiga, variedade 'Manteiga verde crespa" foram colhidas nas primeiras horas da manhã, em horta comercial localizada no perímetro urbano do município de Altamira-PA. As folhas (aproximadamente $10 \mathrm{Kg}$ ) foram imediatamente acondicionadas em caixas térmicas contendo água e gelo e transportadas até o laboratório de Tecnologia de Produtos da Universidade Federal do Pará, Campus Altamira.
No laboratório, as folhas foram selecionadas quanto à incidência de injúrias, defeitos e ou danos cometidos por pragas e doenças. Foram previamente enxaguadas em água corrente e então higienizadas em solução contendo hipoclorito de sódio a $5 \mathrm{mg} \mathrm{L}^{-1}$ por cinco minutos; após sanitização as folhas foram novamente enxaguadas em água corrente a fim de eliminar o excesso do sanificante e então dispostas em bancadas onde permaneceram até estarem completamente secas em temperatura de $20{ }^{\circ} \mathrm{C}$.

Os tratamentos consistiram em: T1 (testemunha), folhas apenas higienizadas; T2: (Radiação gama) as folhas foram tratadas com 1,0 KGy, sendo submetidas a fonte de Cobalto-60 e o irradiador utilizado foi o GAMMABEAN 650, pertencente ao Centro de Estudos Agrários da UHE-Belo Monte localizado no município de Altamira-PA. A determinação da dosagem foi obtida em função da variação do tempo de exposição do fruto à fonte irradiadora como descrito nos tratamentos a seguir: T3 (3\% de amido de milho): as folhas foram imersas por um período de 2 minutos na solução aquosa; T4 (combinação de radiação gama e amido de milho): primeiramente, as folhas foram expostas a dose de radiação de 1,0 KGy e posteriormente mantidas em solução aquosa de amido de milho a 3\%. Após a aplicação de cada tratamento, as folhas foram acondicionadas em sacos de polietileno de baixa densidade (PEBD) e mantidas em refrigerador por 16 dias a temperatura de $8{ }^{\circ} \mathrm{C}$ e $90 \%$ de UR, simulando a comercialização nos pontos de venda.

As folhas de couve foram avaliadas em intervalos de dois dias quanto às características físico-químicas e sensoriais: perda de massa fresca, determinada pela pesagem das folhas em balança analítica, considerando a massa inicial de cada amostra, com os resultados expressos em percentagem.

O teor de clorofila total foi medido de acordo com Yuan et al. (2009). Cerca de 0,5 g de couve foram moídos e extraídos em $10 \mathrm{~mL}$ de acetona $80 \%$. Em seguida, centrifugados por 10 minutos (3000 rpm) e retirados os resíduos. O conteúdo de clorofila total foi determinado pela leitura da absorbância em um espectrofotômetro SHIMADZU, modelo UV-1650PC com leitura a $652 \mathrm{~nm}$, sendo o resultado expresso em $\mathrm{mg} \mathrm{g}^{-1}$ de massa fresca.

As atividades das enzimas polifenoloxidase e peroxidase foram determinadas seguindo a metodologia descrita por Matsuno e Uritani (1972). Os resultados das atividades de polifenoloxidase e peroxidase foram

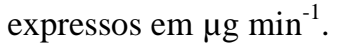

O teor de sólidos solúveis foi determinado por maceração de $10 \mathrm{~g}$ da amostra e análise direta do suco obtido em refratômetro digital tipo Palette PR - 32, marca ATAGO, com compensação de temperatura 
automática e os resultados foram expressos em ${ }^{\circ} \mathrm{Brix}$, conforme AOAC (2007).

A acidez titulável foi determinada através da titulação de uma alíquota de $10 \mathrm{~g}$ de polpa homogeneizada, com solução de $\mathrm{NaOH} \quad(0,1 \mathrm{~N})$ previamente padronizada, com os resultados expressos em mg de ácido cítrico/100g de polpa conforme AOAC (2007). O pH foi mensurado na polpa triturada dos frutos utilizando-se um potenciômetro (Digital DMPH2), segundo a técnica da AOAC (2007).

O murchamento, sabor e a qualidade geral foram avaliados por sete pessoas treinadas pelo método de análise descritiva qualitativa desenvolvida por Stone e Sidel (1992), onde os avaliadores atribuíram notas em uma escala hedônica de pontos, onde: 1 = Péssimo; 2 = Muito Ruim; 3 = Ruim; 4 = Regular; 5 = Bom; $6=$ Muito Bom e 7 = Ótimo.

$\mathrm{O}$ delineamento experimental adotado foi inteiramente casualizado em esquema fatorial $4 \times 9$ (quatro tratamentos e nove tempos de avaliação: 0, 2, 4, $6,8,10,12,14$ e 16 dias), com cinco repetições, sendo três folhas por parcela experimental. Os resultados de cada análise foram submetidos à análise estatística pelo Programa ASSISTAT 7.7 versão beta. Os resultados foram avaliados através da análise de variância ANOVA e pelo teste de Tukey, ambos ao nível de 5\% de significância, a análise de regressão foi realizada por meio do software Microsoft Office Excel

\section{Resultados e Discussão}

De acordo com a Figura 1A, observou-se que não houve interação significativa até o sexto dia sobre o teor de clorofila entre as amostras de couve nos diferentes tratamentos avaliados, provavelmente essa conservação nos dias iniciais está ligada ao ambiente refrigerado no qual foram armazenadas. Zaicovski et al., (2008) em trabalho com brócolis, verificaram que não houve variação significativa nos valores de clorofila nos cinco primeiros dias de armazenamento a $7{ }^{\circ} \mathrm{C}$ devido ao efeito que as baixas temperaturas proporcionam, como menor atividade metabólica e menor degradação de clorofilas.

A partir do sexto dia notou-se uma redução acentuada nos valores de clorofila para o tratamento testemunha (T1) até o fim do armazenamento quando a média verificada foi de $15,4 \mathrm{mg} \mathrm{g}^{-1}$. Para o mesmo período os tratamentos com radiação gama (T2), amido de milho (T3) e da combinação radiação e amido de milho (T4) não diferiram entre si e verificaram uma redução lenta nos valores de clorofila até ao final do experimento com médias em torno de $20 \mathrm{mg} \mathrm{g}^{-1}$ de clorofila, contudo, a associação da radiação gama com o amido de milho (T4) favoreceu as menores reduções
(Figura 1A). Segundo Costa et al. (2005), a redução do teor de clorofila é um indicativo do processo de senescência. Reis et al., (2014) o avaliar folhas de alface durante armazenamento refrigerado também notaram redução nos compostos clorofilicos, considerando este um indicativo de perda de qualidade.

As atividades das enzimas peroxidase e polifenoloxidase apresentaram aumento no decorrer do tempo de armazenamento observando picos mais acentuados nos diferentes tratamentos com posterior estabilização (Figuras 1B e 1C), respectivamente. O aumento dessas enzimas com o tempo de armazenamento também foi observado por Galati et al. (2015) ao avaliarem folhas de alfaces tratadas na précolheita com ácido salicílico. Mattos et al. (2007) explicam que a atividade da peroxidase e polifenoloxidase aumenta devido ao estresse, aumenta radicais livres como peróxidos, gerados na senescência, então a peroxidase vem tentando estabelecer o equilíbrio, para diminuir os peróxidos formados, gerando radicais livres de alto poder oxidante. Yuan et al. (2009) completam afirmando que o aumento da atividade da peroxidase representa uma consequência do processo de senescência

De maneira geral, a atividade das enzimas peroxidase e polifenoloxidase (Figuras 1B e 1C), apresentaram comportamento semelhante no decorrer do tempo de armazenamento, de modo que, o tratamento, testemunha (T1) e com amido de milho (T3) o aumento mais característico foi visualizado nos dias oito e dez, respectivamente. Para as folhas submetidas aos tratamentos com radiação gama na forma isolada (T2) e quando combinado o efeito da radiação com o amido de milho (T4), não houve variação estatística e a maior elevação é percebida somente após o décimo quarto dia, diferindo significativamente dos demais, respectivamente.

O conteúdo de sólidos solúveis variou de $7,8{ }^{\circ}$ Brix no dia zero para 5,3 ${ }^{\circ}$ Brix após dezesseis dias de avaliação. De acordo com a figura $2 \mathrm{~A}$ observou-se uma redução até o oitavo dia de armazenamento, seguido de aumento até o décimo segundo dia e posterior redução até o fim do experimento, em todos os tratamentos. A redução mais expressiva é evidenciada pelos tratamentos testemunha (T1) e com amido de milho (T3) sem interação significativa entre si. O tratamento com radiação gama (T2) apresentou as menores reduções, contudo, não diferiu do tratamento combinado de radiação gama e amido de milho (T4) (Figura 2A). Carnelossi et al. (2002) avaliando folhas de couve minimamente processadas também encontraram variação ao longo do tempo de armazenamento com médias oscilando do início ao fim do experimento entre 7,8 a $5,2{ }^{\circ}$ Brix. 

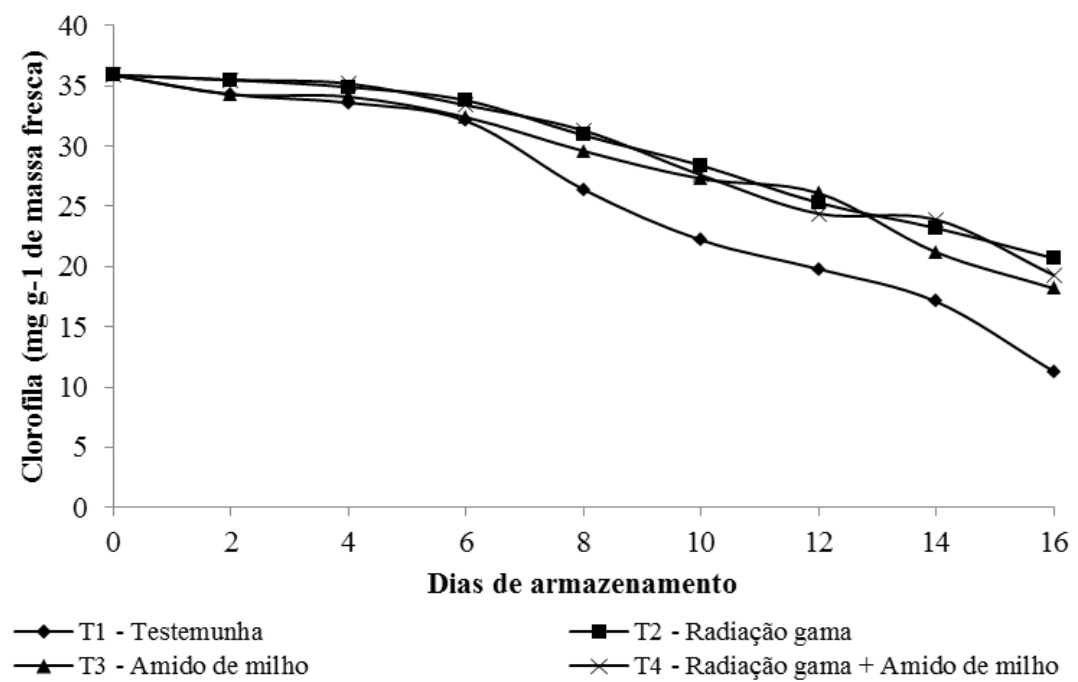

- - T2 - Radiação gama

$\longrightarrow$ T3 - Amido de milho

* T4 - Radiação gama + Amido de milho

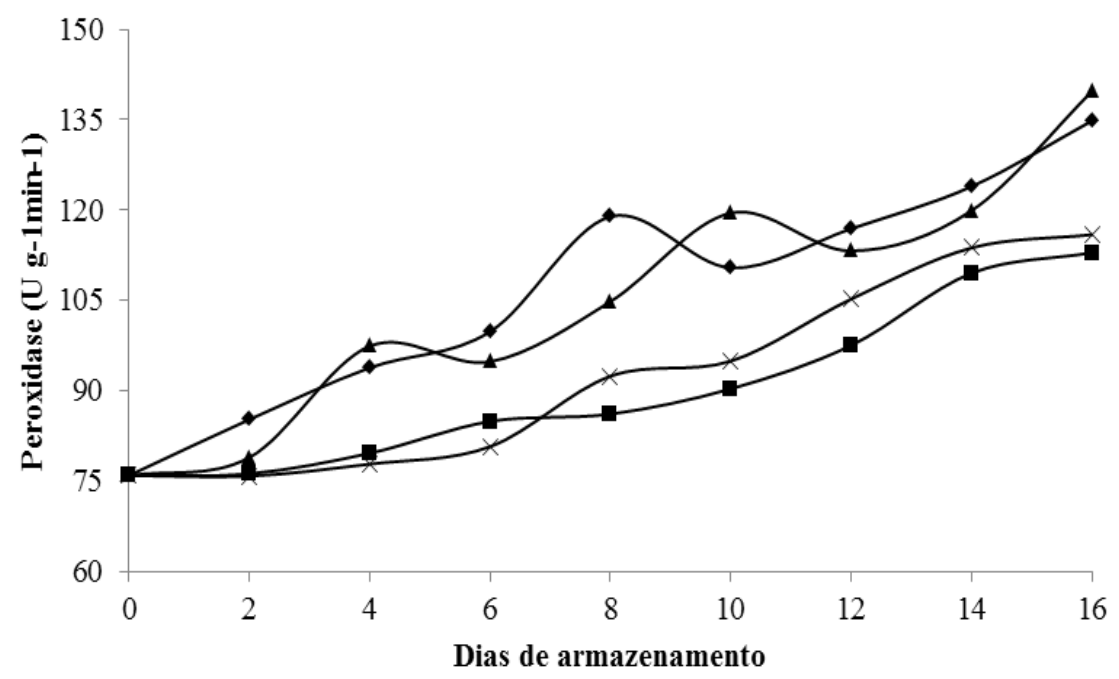

$\longrightarrow \mathrm{T} 1$ - Testemunha

-T2 - Radiação gama

Ł-T3 - Amido de milho

$\multimap$ T4 - Radiação gama + Amido de milho

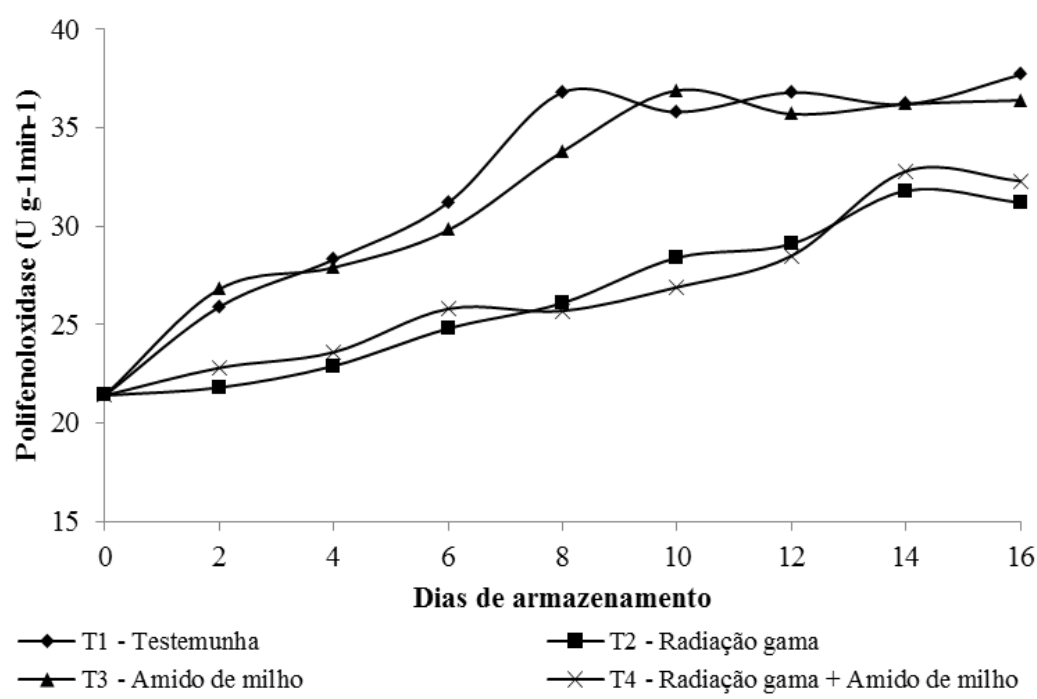

Figura 1. Variação nos teores de clorofila (A) e atividade das enzimas peroxidase (B) e polifenoloxidase (C) em folhas de couve manteiga submetidas a diferentes tratamentos de conservação pós-colheita. 
Os valores para sólidos solúveis, $\mathrm{pH}$ e acidez titulável (Figuras 2A, 2B e 2C) apresentaram diferença estatística entre os tratamentos utilizados verificando ainda grande variação nos valores ao longo de todo o tempo de armazenamento. Os valores de $\mathrm{pH}$ apresentaram pouca variação entre os tratamentos com radiação gama e quando houve o efeito combinado radiação gama e amido de milho (T4) ao longo do tempo de armazenamento. Nos tratamentos, testemunha (T1) e com amido de milho (T3), observa-se um incremento nos valores médios até o oitavo dia seguido de redução ao décimo segundo com posterior aumento até o fim do experimento (Figura 2B). Essa maior oscilação durante o armazenamento é explicada pela metabolização dos compostos bioquímicos durante a atividade respiratória, indicando desta forma perdas importantes nos constituintes químicos presentes nas folhas (CHITARRA; CHITARRA, 2007).

De modo geral todos os tratamentos apresentaram um incremento nos valores médios de $\mathrm{pH}$ no terço final de armazenamento apresentando médias de 6,42, 6,16, 6,38 e 6,19 para os tratamentos testemunha (T1), radiação gama (T2), amido de milho (T3) e radiação gama e amido de milho (T4), respectivamente após dezesseis dias (Figura 2B). Valores semelhantes aos verificados nesta pesquisa foram determinados por Pereira et al., (2015) que ao avaliar folhas de couve manteiga encontraram variação do $\mathrm{pH}$ entre 6,34 a 6,46 durante o armazenamento refrigerado. Para Chitarra e Chitarra (2007), o aumento de $\mathrm{pH}$ durante o armazenamento pode estar relacionado ao desdobramento do amido em açúcares redutores e sua conversão em ácido pirúvico provocada pela respiração, como também está associado à redução de acidez em razão da senescência.

A acidez titulável apresentou oscilação dos seus valores durante o período de armazenamento. Devido essa oscilação foi encontrado um ponto de máximo e outro de mínimo, sendo o máximo de 0,33 g/100 g ácido cítrico ao oitavo dia de armazenamento e o mínimo aos dezesseis dias de armazenamento com média de 0,09 g/100 g ácido cítrico (Figura 2C). Segundo Roura et al. (2000), logo após a colheita, o tecido vegetal tem maior respiração, decrescendo acentuadamente a acidez devido ao consumo dos ácidos orgânicos no processo respiratório, na tentativa de se manter em seu estado inicial. Já o aumento na acidez de produtos armazenados por curtos períodos pode ser explicado pela geração de radicais (ácidos galacturônico) a partir da hidrólise dos constituintes da parede celular, em especial, as pectinas.

De modo geral, os valores da acidez, ao longo do armazenamento, apresentaram comportamento semelhante ao verificado por Carnelossi et al. (2002) que ao avaliarem folhas de couve sob atmosfera modificada notaram um aumento nos dias iniciais seguido de redução no terço final de armazenamento. As menores variações foram verificadas pelo tratamento isolado da radiação gama (T2) alcançando média de $0,18 \mathrm{~g} / 100 \mathrm{~g}$ ácido cítrico no final do armazenamento. $\mathrm{O}$ tratamento combinado de radiação gama e amido de milho (T4) apresentou média semelhante ao tratamento com amido de milho na forma isolada (T3), 0,14 e 0,13 $\mathrm{g} / 100 \mathrm{~g}$ ácido cítrico respectivamente. As folhas de couve do tratamento testemunha (T1) apresentaram média de 0,6 g/100g ácido cítrico (Figura 2C). A perda de massa fresca propicia danos econômicos significativos não somente na quantidade, mas também na qualidade a ser comercializada. Independente do tratamento utilizado notou-se um aumento linear na perda de massa em todos os tratamentos (Tabela 1).

$\mathrm{O}$ tratamento combinado de radiação gama e amido de milho (T4) e o efeito isolado da radiação gama (T2) não diferiram entre si e apresentaram menor perda de massa nas amostras com médias ao final do armazenamento, médias de $8,76 \%$ e $8,69 \%$, respectivamente. Os percentuais apresentados pela testemunha (T1) foram bem inferiores aos demais tratamentos com média superior a $7 \%$ após oito dias de armazenamento e alcançando percentual de $13,93 \%$ no fim do experimento (Tabela 1).

Chitarra e Chitarra (2005) argumentam que algumas folhosas têm sua comercialização comprometida com perda de massa de apenas 4\%. Enquanto, outras são prejudicadas efetivamente apenas com perdas de massa acima de $7 \%$. Neste experimento, notou-se que até o décimo segundo dia as folhas de couve correspondentes aos tratamentos radiação gama e amido de milho (T4) e radiação gama (T2) apresentavam médias de 6,87 e $6,71 \%$, respectivamente. As médias para qualidade geral, murchamento e sabor apresentaram variação estatística entre si ao nível de 5\% de probabilidade ao longo do período de armazenamento. Para as variáveis murchamento e qualidade geral os avaliadores atribuíram notas similares no decorrer do tempo de armazenamento (Tabela 1), tal fato deve-se a singularidade existente entre as mesmas, de modo que a qualidade geral, está intimamente ligada à aparência do produto, neste caso, o murchamento.

Segundo Nunes et al (2013), a presença de folhas com murchamento é natural devido à perda de clorofila e água e são utilizadas como um indicativo de baixa qualidade e imprópria para o consumo. Os tratamentos, testemunha (T1) e amido de milho (T4) apresentaram nota 4 "regular'" após seis dias de armazenamento, enquanto que nas folhas de couve tratadas com radiação gama (T2) e o combinado de radiação gama e amido de milho (T4) apresentaram esta nota somente a partir do décimo segundo dia mantendo-se até o fim do armazenamento e não diferindo entre si (Tabela 1). 

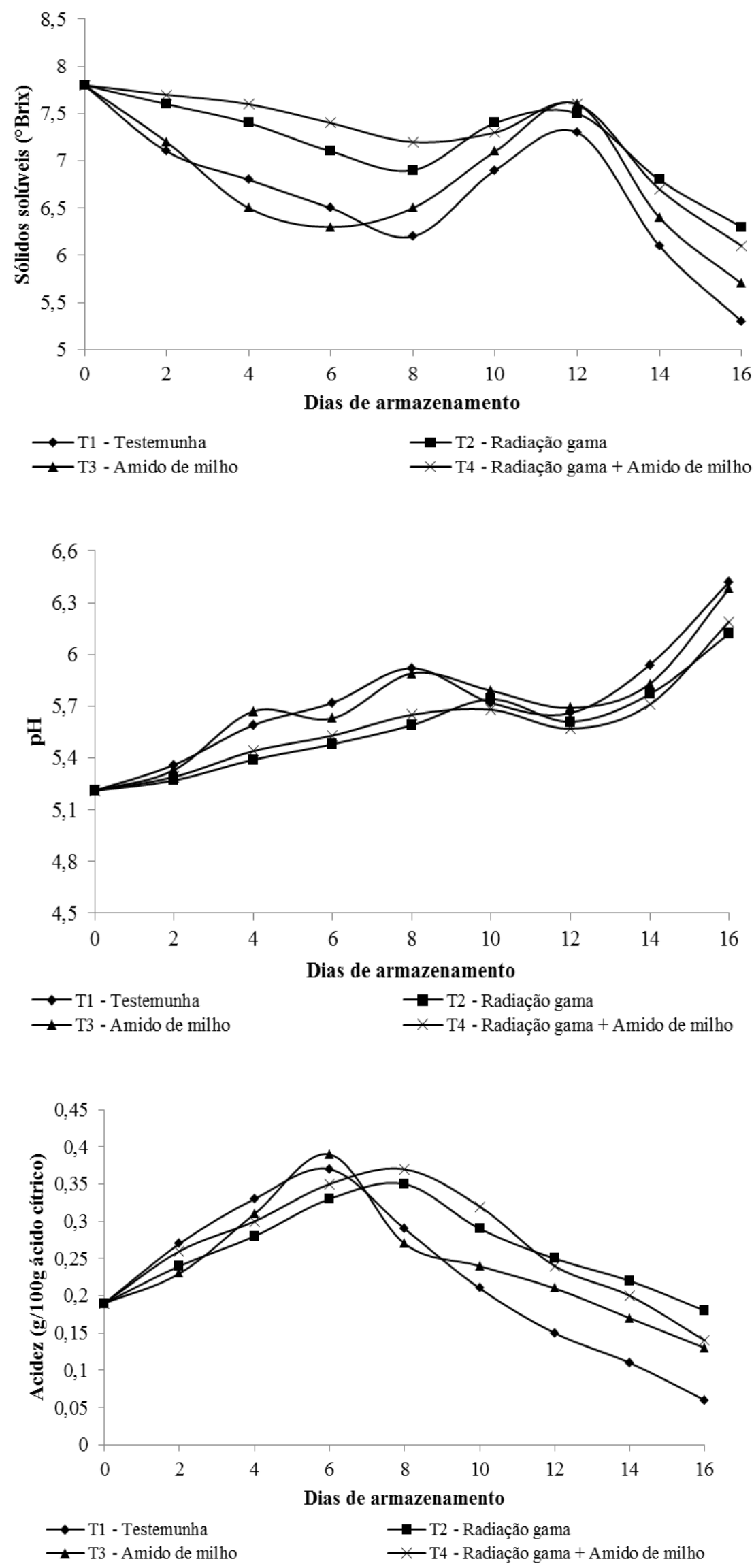

Figura 2. Oscilação nos valores de sólidos solúveis (A), pH (B) e acidez titulável (C) em folhas de couve manteiga submetidas a diferentes tratamentos de conservação pós-colheita. 
Tabela 1: Média sobre as variáveis: perda de massa fresca, murchamento, aparência geral e sabor em folhas de couve manteiga submetidas a diferentes tratamentos de conservação pós-colheita.

\begin{tabular}{|c|c|c|c|c|}
\hline \multirow[t]{2}{*}{ Dias de armazenamento } & \multicolumn{4}{|c|}{ Perda de massa fresca $(\%)$} \\
\hline & Testemunha & Radiação gama & Amido de milho & $\begin{array}{l}\text { Radiação gama + } \\
\text { Amido de milho }\end{array}$ \\
\hline 0 & $0,00 \mathrm{aA}$ & $0,00 \mathrm{aA}$ & $0,00 \mathrm{aA}$ & $0,00 \mathrm{aA}$ \\
\hline 2 & $2,87 \mathrm{cA}$ & $0,58 \mathrm{aA}$ & $1,93 \mathrm{bA}$ & $0,92 \mathrm{aA}$ \\
\hline 4 & $4,93 \mathrm{bAB}$ & 1,49 aA & $3,96 \mathrm{abA}$ & $1,52 \mathrm{aA}$ \\
\hline 6 & $6,33 \mathrm{cB}$ & $2,87 \mathrm{aA}$ & $5,87 \mathrm{bAB}$ & $2,69 \mathrm{aA}$ \\
\hline 8 & $7,21 \mathrm{cB}$ & $3,62 \mathrm{aA}$ & $6,92 \mathrm{bcB}$ & $3,91 \mathrm{aAB}$ \\
\hline 10 & $9,12 \mathrm{cC}$ & $4,65 \mathrm{aAB}$ & $8,93 \mathrm{cC}$ & $4,98 \mathrm{aB}$ \\
\hline 12 & $11,08 \mathrm{cC}$ & $6,71 \mathrm{aB}$ & $10,17 \mathrm{bC}$ & $6,87 \mathrm{aB}$ \\
\hline 14 & $12,61 \mathrm{bD}$ & $7,36 \mathrm{aB}$ & $12,54 \mathrm{bD}$ & $7,53 \mathrm{aB}$ \\
\hline 16 & $13,93 \mathrm{bD}$ & $8,69 \mathrm{aC}$ & $13,81 \mathrm{bD}$ & $8,76 \mathrm{aC}$ \\
\hline \multicolumn{5}{|c|}{$\mathrm{CV}(\%)=3,92$} \\
\hline Dias de armazenamento & \multicolumn{4}{|c|}{ Murchamento } \\
\hline 0 & $7,00 \mathrm{aA}$ & $7,00 \mathrm{aA}$ & $7,00 \mathrm{aA}$ & $7,00 \mathrm{aA}$ \\
\hline 2 & $6,00 \mathrm{bB}$ & $7,00 \mathrm{aA}$ & $6,00 \mathrm{bB}$ & $7,00 \mathrm{aA}$ \\
\hline 4 & $5,00 \mathrm{cBC}$ & $7,00 \mathrm{aA}$ & $6,00 \mathrm{bB}$ & $7,00 \mathrm{aA}$ \\
\hline 6 & $4,00 \mathrm{bBC}$ & $6,00 \mathrm{aAB}$ & $4,00 \mathrm{bBC}$ & $6,00 \mathrm{aB}$ \\
\hline 8 & $3,00 \mathrm{cC}$ & $6,00 \mathrm{aAB}$ & $4,00 \mathrm{bBC}$ & $6,00 \mathrm{aB}$ \\
\hline 10 & $3,00 \mathrm{cC}$ & $5,00 \mathrm{aB}$ & $4,00 \mathrm{bBC}$ & $6,00 \mathrm{aB}$ \\
\hline 12 & $2,00 \mathrm{cD}$ & $4,00 \mathrm{aC}$ & $3,00 \mathrm{bC}$ & $4,00 \mathrm{aC}$ \\
\hline 14 & $2,00 \mathrm{cD}$ & $4,00 \mathrm{aC}$ & $3,00 \mathrm{bD}$ & $4,00 \mathrm{aC}$ \\
\hline 16 & $1,00 \mathrm{cE}$ & $4,00 \mathrm{aC}$ & $2,00 \mathrm{bD}$ & $4,00 \mathrm{aC}$ \\
\hline \multicolumn{5}{|c|}{$\mathrm{CV}(\%)=8,54$} \\
\hline Dias de armazenamento & \multicolumn{4}{|c|}{ Qualidade geral } \\
\hline 0 & $7,00 \mathrm{aA}$ & $7,00 \mathrm{aA}$ & $7,00 \mathrm{aA}$ & $7,00 \mathrm{aA}$ \\
\hline 2 & $6,00 \mathrm{bAB}$ & $7,00 \mathrm{aA}$ & $6,00 \mathrm{bAB}$ & $7,00 \mathrm{aA}$ \\
\hline 4 & $4,00 \mathrm{cB}$ & $7,00 \mathrm{aA}$ & $5,00 \mathrm{bB}$ & $7,00 \mathrm{aA}$ \\
\hline 6 & $4,00 \mathrm{cB}$ & $6,00 \mathrm{aAB}$ & $4,00 \mathrm{bBC}$ & $6,00 \mathrm{bAB}$ \\
\hline 8 & $3,00 \mathrm{cC}$ & $6,00 \mathrm{aAB}$ & $4,00 \mathrm{bBC}$ & $6,00 \mathrm{bAB}$ \\
\hline 10 & $3,00 \mathrm{cc}$ & $6,00 \mathrm{aAB}$ & $3,00 \mathrm{bC}$ & $6,00 \mathrm{bAB}$ \\
\hline 12 & $2,00 \mathrm{bD}$ & $4,00 \mathrm{aB}$ & $2,00 \mathrm{bD}$ & $4,00 \mathrm{aB}$ \\
\hline 14 & $1,00 \mathrm{cE}$ & $4,00 \mathrm{aB}$ & $2,00 \mathrm{bD}$ & $4,00 \mathrm{aB}$ \\
\hline 16 & $1,00 \mathrm{cE}$ & $4,00 \mathrm{aB}$ & $2,00 \mathrm{bD}$ & $4,00 \mathrm{aB}$ \\
\hline \multicolumn{5}{|c|}{$\mathrm{CV}(\%)=6,82$} \\
\hline Dias de armazenamento & & & & \\
\hline 0 & $7,00 \mathrm{aA}$ & $7,00 \mathrm{aA}$ & $7,00 \mathrm{aA}$ & $7,00 \mathrm{aA}$ \\
\hline 2 & $6,00 \mathrm{bAB}$ & $7,00 \mathrm{aA}$ & $6,00 \mathrm{bAB}$ & $7,00 \mathrm{aA}$ \\
\hline 4 & $5,00 \mathrm{cB}$ & $7,00 \mathrm{aA}$ & $6,00 \mathrm{bAB}$ & $7,00 \mathrm{aA}$ \\
\hline 6 & $4,00 \mathrm{cC}$ & $6,00 \mathrm{aB}$ & $5,00 \mathrm{abB}$ & $6,00 \mathrm{aB}$ \\
\hline 8 & $3,00 \mathrm{cD}$ & $6,00 \mathrm{aB}$ & $4,00 \mathrm{bC}$ & $5,00 \mathrm{aBC}$ \\
\hline 10 & $*$ & $6,00 \mathrm{aB}$ & $3,00 \mathrm{cD}$ & $4,00 \mathrm{aC}$ \\
\hline 12 & $*$ & $4,00 \mathrm{aC}$ & $*$ & $4,00 \mathrm{aC}$ \\
\hline 14 & $*$ & $4,00 \mathrm{aC}$ & * & $4,00 \mathrm{aC}$ \\
\hline 16 & $*$ & $4,00 \mathrm{aC}$ & $*$ & $3,00 \mathrm{aD}$ \\
\hline
\end{tabular}

Médias seguidas pela mesma letra na coluna (maiúsculas) e linha (minúsculas) não diferem entre si pelo teste de Tukey a 5\% de probabilidade. *amostras não avaliadas por conta do elevado estado de senescência.

\section{Conclusões}

O tratamento isolado com radiação gama apresentou os melhores resultados contribuindo na longevidade das folhas de couve manteiga sobre as variáveis físicoquímicas e sensoriais por até 16 dias.
O amido de milho quando comparado ao controle apresenta resultados satisfatórios na conservação póscolheita desta folhosa.

A vida de prateleira foi de 8, 10, 14 e 16 dias para os tratamentos controle, amido de milho, combinação da radiação gama com o amido de milho e radiação gama isolada, respectivamente. 


\section{Referências Bibliográficas}

AOAC. ASSOCIATION OF OFFICIAL ANALYTICAL CHEMISTS. Offifial methods of the association of the agricultural Chemists. $17^{\text {th }}$ ed. Waschington-USA: AOAC, 2007. $1410 \mathrm{p}$

ALVES, A. I.; SARAIVA, S. H.; LUCIA, S. M. D.; TEIXEIRA, L. J. Q.; JUNQUEIRA, M. S. Qualidade de morangos envolvidos com revestimento comestível antimicrobiano à base de diferentes fontes de amido. Revista Enciclopédia Biosfera, Centro Científico Conhecer, Goiânia-GO, v.7, n. 13, p. 1519-1526, 2011.

AZEREDO H. M. C.; FARIA J. A. F.; AZEREDO A. M. C. Embalagens Ativas para Alimentos. Ciência e Tecnologia de Alimentos, Lavras-MG, v. 20, n. 3, p. 89-96, 2000.

CARNELOSSI, M. A. G.; SILVA, E. O.; CAMPOS, R. S.; SOARES, N. F. F.; MINIM, V. P. R.; PUSCHMANN, R. Conservação de folhas de couve minimamente processadas. Revista Brasileira de Produtos Agroindustriais, Campina Grande-PB, v.4, n.2, p.149-155, 2002.

Chitarra, M. I. F, Chitarra, A. B. Pós-colheita de frutos e hortaliças: fisiologia e manuseio. $2^{\mathrm{a}}$ ed. Lavras-MG: Editora UFLA, 2005.

CHITARRA, M. I. F.; CHITARRA, A. B. Processamento mínimo de alface. In: Manual de Processamento Mínimo de Frutas e Hortaliças. Brasília-DF: Embrapa Hortaliças e SEBRAE. 513p. 2007.

COSTA, M. L.; CIVELlO, P. M.; CHAVES, A. R.; MARTINEZ, G. A. Effect of ethephon and 6benzylaminopurine on chlorophyll degrading enzymes and a peroxidase - linked chlorophyll bleaching during postharvest senescence of broccoli (Brassica oleracea L.) at $20^{\circ} \mathrm{C}$. Postharvest Biology and Technology, Madison-USA, v. 35, n. 3, p. 191-199, 2005.

FILGUEIRA, F. A. R. Novo manual de olericultura: Agrotecnologia moderna na produção e comercialização de hortaliças. Viçosa-MG: UFV, 2003, 402 p.

GALATI, V. C.; GUIMARÃES, J. E. R.; MARQUES, K. M.; FERNANDES, J. D. R.; CECÍLIO-FILHO, A. B.; MATTIUZ, B. H. Aplicação de silício, em hidroponia, na conservação pós-colheita de alface americana 'Lucy Brown' minimamente processada. Revista Ciência Rural, Santa Maria-RS, v. 3, n. 4, p. 34-39, 2015.

MATTOS, L. M.; MORETTI, C. L.; CHITARRA, A. B.; PRADO, M. E. T. Qualidade de alface crespa minimamente processada armazenada sob refrigeração em dois sistemas de embalagem. Horticultura Brasileira, Brasília-DF, v. 25, n. 4, p.504-508, 2007.
MATSUNO, H.; URITANI, I. Physiological behavior of peroxidase isozymes in sweet potato root tissue injured by cutting or with black rot. Plant and Cell Physiology, KyotoJP, v. 13, n. 1, p.1091-1101, 1972.

NOVO, M. C. S. S.; PRELA-PANTANO, A.; TRANI, P. E.; BLAT, S. F. Desenvolvimento e produção de genótipos de couve manteiga. Revista Horticultura Brasileira. BrasíliaDF, v. 28, n. 3, p. 321-325, 2010.

NUNES, C. J. dos. S. SOUZA, M. L. de.; FERREIRA, R. L. F. Qualidade e vida útil da rúcula orgânica armazenada sob refrigeração. Revista Enciclopédia Biosfera, Centro Científico Conhecer, Goiânia-GO, v. 9, n.17; p. 2231-2240, 2013.

PEREIRA, E. M.; SANTOS, Y. M. G. dos.; LEITE-FILHO, M. T.; FRAGOSO, S. P.; PEREIRA, B. B. M. Qualidade póscolheita de frutas e hortaliças cultivadas de forma orgânica. Revista Verde de Agroecologia e Desenvolvimento Sustentável. Pombal-PB, v. 10, n.2, p. 56 - 60, 2015.

REIS, H. F.; MELO, C. M.; MELO, E. P.; SILVA, R. A.; SCALON, S. P. Q. Conservação pós-colheita de alface crespa, de cultivo orgânico e convencional, sob atmosfera modificada. Horticultura Brasileira, Brasília-DF, v. 32, n. 3, p. 303-309, 2014.

ROURA, S. I.; DAVIDOVICH, L. A.; DEL VALLE, C. E. Quality loss in minimally processed swiss chard related to amount of damaged area. Lebensmittel-Wissenschaft und Technology, Londres-UK, v.23, n.1, p.53-59, 2000.

STONE, H.; SIDEL, J. L. Sensory evaluation practices. $2^{\text {nd }}$ ed. San Diego-USA: Editora Academic Press, 1992. 308 p.

VIEITES, R. L.; PICANÇO, N. F. M.; DAIUTO, E. R. Radiação gama na conservação de caqui 'giombo', destanizado e frigoarmazenado. Revista Brasileira de Fruticultura, Jaboticabal-SP, v. 34, n. 3, p. 719-726, 2012.

YUAN, M.; CHE, X.; YUAN, R.; CHAI, Y. Hydrogen peroxide sensor based on horseradish peroxidase immobilized on an electrode modified with DNA-L-cysteine-gold-platinum nanoparticles in polypyrrole film. Revista Microchimica Acta, Berlim-GER, v. 2, n. 5, p. 159-167, 2009.

ZAICOVSKI, C. B.; MORENO, M. B.; ROMBALDI, C. V. Efeito de danos mecânicos, da redução de temperatura e 1MCP no metabolismo pós-colheita de brócolis Legacy. Ciência e Tecnologia de Alimentos, Campinas-SP, v.28, n.4, p.840-845, 2008. 